https://doi.org/10.21670/ref.2017.37.a06

Artículos

\title{
Propuesta de un modelo de análisis de estrategias de colaboración sindical transfronteriza
}

\section{Proposal for a model for analyzing strategies for cross-border trade union collaboration}

Jesús Rubio Campos a* (D)https://orcid.org/0000-0001-5381-732X
Recibido el 2 de noviembre de 2016. Aceptado el 15 de agosto de 2017.

*Autor para correspondencia: Jesús Rubio Campos, correo electrónico: rubio@colef.mx

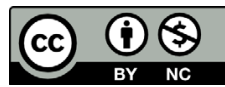

Esta obra está protegida bajo una Licencia Creative Commons Atribución-NoComercial 4.0 Internacional.
${ }^{a}$ El Colegio de la Frontera Norte, Departamento de Estudios de Administración Pública, Sede Monterrey, Nuevo León, México, correo electrónico: rubio@colef.mx

\section{Resumen}

El objetivo de la presente investigación es analizar la eficacia de la colaboración sindical transfronteriza para enfrentar los efectos adversos de la globalización sobre las condiciones laborales. La metodología utilizada es la comparada, con casos de América del Norte y la Unión Europea. En un primer nivel de análisis, los casos se dividieron en cuatro tipologías y en un segundo se construyeron dos categorías, la intensidad y eficacia de la colaboración, con variables de graduación al interior de cada categoría. El valor del estudio reside en la nueva propuesta de modelo de análisis y la cantidad de casos revisados, pero una limitación es su carácter exploratorio. Se encontró que la colaboración sindical transfronteriza resulta una estrategia eficaz para enfrentar los efectos adversos de la globalización sobre las condiciones laborales, en diversos grados dependiendo de la institucionalización y frecuencia de colaboración.

Palabras clave: sindicatos, colaboración sindical transfronteriza, TLCAN, Unión Europea.

\section{Abstract}

The aim of the present research is to analyze the effectiveness of cross-border union collaboration to address the adverse effects of globalization on working conditions. The methodology used is compared analysis, with cases from North America and the European Union. In a first level of analysis, the cases were divided into four typologies and in a second level two categories were constructed, the intensity and effectiveness of the collaboration, with graduation variables within each category. The value of the study lies in the new proposed model of analysis and the number of cases reviewed, but one limitation is its exploratory nature. It was found that cross-border union collaboration result an

CÓMO CITAR: Rubio, J. (2017). Propuesta de un modelo de análisis de estrategias de colaboración sindical transfronteriza [Proposal for a model for analyzing strategies for cross-border trade union collaboration]. Estudios Fronterizos, 18(37), 103-130, doi:10.21670/ref.2017.37.a06 
effective strategy to address the adverse effects of globalization on labor conditions, to varying degrees depending on institutionalization and frequency of collaboration.

Keywords: unions, cross-border trade union cooperation, NAFTA, European Union.

\section{Introducción}

La pregunta que guía la presente investigación es si la colaboración sindical transfronteriza ayuda a enfrentar los efectos adversos de la globalización sobre las condiciones laborales, derivadas de la capacidad de deslocalización de las transnacionales, la fragmentación de las organizaciones de trabajadores y la tendencia a disminuir derechos de los trabajadores en aras de atraer inversión extranjera directa.

Por ello, el objetivo de esta investigación es analizar las diferentes experiencias de colaboración sindical transfronteriza que se han suscitado a partir del último cuarto del siglo pasado, para conocer si son eficaces o no para enfrentar los efectos adversos de la globalización sobre las condiciones laborales, utilizando para ello un modelo teórico creado ex profeso a partir de la revisión de la literatura más reciente sobre el tema.

En el presente trabajo se define a la colaboración sindical transfronteriza como una estrategia defensiva, planeada y ejecutada por los trabajadores organizados, para reforzar la protección de sus condiciones laborales y evitar la potencial precarización derivada de los procesos de apertura comercial y los movimientos de deslocalización de la inversión extranjera directa, formando y haciendo uso de redes de organizaciones de trabajadores y sociales a nivel transnacional para potenciar la defensa de sus intereses, mediante recursos como: financiamiento, asesoría, búsqueda de homologación de condiciones laborales, protección de derechos sindicales, presión y apoyo público entre sindicatos y actores sociales de diversos países que tienen intereses comunes.

La metodología de investigación utilizada en una primera etapa consistió en una revisión de fuentes documentales especializadas en colaboración sindical transfronteriza, provenientes de revistas académicas internacionales arbitradas por pares, la cual, se muestra en el primer apartado denominado marco teórico. A partir de dicha revisión, en la segunda sección la metodología se fortalece con la propuesta de un modelo de análisis comparado, compuesto de categorías y tipologías de colaboración sindical transfronteriza.

Utilizando dicho modelo comparado, en la tercera sección se analizan ocho diferentes experiencias de colaboración sindical transfronteriza, que fueron incluidas en el presente trabajo para procurar que se tomaran en cuenta todas las formas de colaboración sindical encontradas a nivel nacional e internacional en dicha revisión bibliográfica, para contar con un cuerpo empírico susceptible de ser analizado mediante el modelo propuesto, el cual se nutrió de la literatura revisada y fue refinado a partir de las mismas experiencias.

Los casos encontrados en esta revisión bibliográfica fueron muy diversos. En un primer nivel de selección, se procuró incluir tanto experiencias mexicanas como internacionales. Algunas experiencias encontradas se refieren a la relación entre sindicatos por iniciativa propia, y otras, a una relación cobijada bajo el manto de acuerdos comerciales internacionales o por formar parte de cadenas de valor. Se incluyeron todos los casos señalados, pues aunque no necesariamente son comparables en todos los aspectos, nos muestran diversos tipos de colaboración sindical existentes de los cuales se pueden extraer importantes aprendizajes. 
Se analizaron las siguientes experiencias de colaboración sindical internacional:

- El Sindicato Nacional de Trabajadores Mineros, Metalúrgicos, Siderúrgicos y Similares de la República Mexicana (SNTMMSRm)

- El Sindicato Mexicano de Electricistas (SME)

- La Red de Solidaridad de la Maquila (RSM)

- La United Students Against Sweatshops (USAs)

- Las National Administrative Offices (NAO), instaladas por el Acuerdo de Cooperación Laboral de América del Norte (NAALC), en el marco de Tratado de Libre Comercio de América del Norte (tLCAN) entre México, Estados Unidos y Canadá

- Los Consejos Sindicales Intrarregionales Europeos (CSIR)

- Los Consejos Europeos del Trabajo (CET)

- Los Acuerdos Marco Internacionales (АмI)

Se espera que la presente investigación constituya un aporte a la discusión teórica y la comprensión empírica de la colaboración sindical transfronteriza a partir de las experiencias analizadas, aprender de ellas, así como conocer los retos que esta enfrenta.

\section{Marco teórico}

Sí bien puede considerarse que el internacionalismo sindical obrero comenzó desde la segunda mitad del siglo xviII con la Asociación Internacional de Trabajadores o Primera Internacional de los Trabajadores y la Segunda Internacional, mientras que para principios del siglo xIx se había formado ya la Federación Internacional de Sindicatos que apoyaba financieramente a huelguistas entre países (Brown, 1928; Wills, 1998), su desarrollo más reciente tiene su antecedente en la época de la Guerra Fría, cuando existían dos grandes organizaciones rivales, la Federación Mundial de Sindicatos de ascendencia comunista y la Confederación Internacional de Sindicatos Libres, de tintes socialistas y una tercera más pequeña, la Confederación Mundial del Trabajo, de tendencia cristiana democrática (Sadler, 2000, p. 137).

Una vez que la Guerra Fría terminó, los sindicatos se han visto forzados a buscar nuevos aliados, en un movimiento que podría llamarse "nuevo internacionalismo laboral" (Wills, 1998) y en el que se ha migrado de un movimiento con fines ideológicos a uno más pragmático. En ese sentido, Hanagan (2003) señala que la solidaridad transnacional moderna como proceso de formación de identidad, ya no es simplemente que los trabajadores se reconozcan como iguales frente a frente, sino que ahora es deliberativa, contempla alternativas y se hacen elecciones de cursos de acción.

Lo anterior se hace más necesario a raíz de los procesos de integración socio económica de la última quinta parte del siglo pasado y la mayor capacidad de movimiento de las inversiones de empresas internacionales que se han acelerado en el esquema post fordista, que han hecho que el mercado laboral de las naciones se haya reconfigurado y hecho cada vez más flexible (Harvey, 1998, p. 143), enfrentando enormes retos debido a la mayor competencia de las naciones por atraer mayor inversión extranjera directa. 
Según autores como Castel (2002, p. 13), la situación actual del empleo está marcada por "la precarización de las condiciones de trabajo, lo inadecuado de los sistemas clásicos de protección y la multiplicación de individuos que ocupan en la sociedad una posición de trabajadores temporales, inempleables, desempleados o empleados de manera precaria”.

Para Wills (1998, p. 111) hay dos posibles interpretaciones del impacto de la globalización económica y la movilidad de capital en busca de mayores rendimientos sobre la organización de la clase trabajadora; la primera es que los sindicatos quedan impotentes ante el poder de las multinacionales para proteger sus derechos y la segunda que la erosión de las barreras nacionales permite a los trabajadores hacer conexiones a través de los territorios.

Esas conexiones se facilitan actualmente por el uso de las tecnologías basadas en internet como herramientas de organización de la acción colectiva y la documentación de casos, como las redes sociales, los portales noticiosos de los sindicatos, las video llamadas por Skype, conversaciones por WhatsApp y el uso de Youtube, entre otros, herramientas que al igual que han sido utilizadas por las ciudadanos comunes y empresas, están siendo aprovechadas por los sindicatos para formar y consolidar redes trasnacionales.

Así, para autores como Beneyto (2016, p. 84), se está dando un "giro estratégico operado en el sindicalismo global, que habría superado las proclamas rituales contra la globalización para implementar una acción sindical en la globalización”.

Las empresas multinacionales en su afán por minimizar costos y maximizar ganancias para participar en la competencia internacional de bienes y servicios llevan a cabo negociaciones contractuales con los sindicatos de los países donde se instalarán, exigiendo frecuentemente salarios y condiciones laborales cada vez menores a las de sus países de origen o de otras naciones donde tienen la opción de instalarse. Para Beneyto (2016, p. 74), esto se da en un contexto donde los sindicatos han visto debilitados sus recursos tradicionales como la representación, la interlocución y la presión.

Esa competencia ha hecho que algunos países tengan comportamientos del tipo social dumping o whipsawing, es decir, un medio de atracción de inversiones de capital sobre la base de bajos salarios, peores condiciones laborales y regulaciones débiles (Alves y Rego, 2012, p. 414; Beneyto, 2016, p. 68; Wills, 1998, p. 113). Para Beneyto (2016, p. 64), ni las leyes nacionales, ni las instituciones internacionales han sido capaces, hasta ahora, de contrarrestar eficazmente estos comportamientos.

Lo anterior ha llevado a los sindicatos locales y nacionales a establecer estrategias colectivas sectoriales y regionales defensivas para no caer en una espiral bajista en las condiciones laborales cada vez más precarias, tanto en sus dimensiones salariales, como de prestaciones, acceso a la seguridad social, servicios de salud, duración de los contratos, así como condiciones de seguridad y comodidad en el lugar de trabajo. Estas estrategias, según autores como Carr (1999) son parte de una posición más amplia de resistencia en contra de la globalización capitalista, la flexibilización del trabajo y los recortes a los sistemas de seguridad social.

Dichas estrategias sindicales tienen el objetivo de establecer estándares en las condiciones contractuales en diversos países o regiones, a fin de que los trabajadores no se vean afectados por dichos procesos de competencia internacional, reducción de costos y maximización de utilidades y conllevan la necesidad de establecer negociaciones mediante herramientas persuasivas con representantes sindicales de diversos países donde las empresas de un sector económico en cuestión tienden a instalarse, así como proveer diversos tipos de apoyo y aprendizaje. Carr (1999) señala 
que la integración económica regional también puede promover la globalización del internacionalismo sindical desde abajo, aunque sea contra los deseos de ciertos arquitectos del proceso de integración. Similarmente, Kay (2005, p. 719) sostiene que las instituciones de gobernanza global estimulan la emergencia de movimientos sociales transnacionales al crear nuevas estructuras de oportunidad política, que junto con actores sociales que se relacionan entre ellos, constituyen un campo de acción política emergente.

Para Hopkins y Wallerstein, (citados en Hanagan, 2003), las cadenas mundiales de bienes entendidas como redes de procesos de producción del trabajo que resultan en un bien final, son muy importantes en la construcción de solidaridad internacional. Lo anterior porque la colaboración sindical transfronteriza para la protección de los intereses de los trabajadores puede organizarse desde abajo a través de la participación de los sindicatos de toda la cadena de valor y de los consumidores del producto final. Para Williams, (como se citó en Carr, 1999), las primeras iniciativas de asociación sindical transfronteriza fueron efímeras, con una alta de fracasos y un poder de resistencia limitado, pero eso parece estar cambiando, pues como menciona Sadler (2000), el trabajo puede ser fortalecido por la solidaridad internacional al brindar recursos y presión más allá del ámbito nacional.

Autoras como Kay (2005, p. 725) proponen un modelo del proceso que se sigue para llevar a cabo la colaboración sindical transfronteriza, que consta de cinco etapas: 1) contacto inicial, 2) interacción y mezcla de intereses, 3) crecimiento de la confianza, 4) acciones conjuntas o de apoyo a necesidades e intereses mutuos y 5) incorporación de intereses mutuos.

Waterman, citado por Wills (1998, p. 119), sugiere los siguientes principios para impulsar la colaboración sindical internacional: 1) priorizar las relaciones cara a cara entre los trabajadores en las bases, los lugares de trabajo a nivel de planta, o en sus comunidades; 2) estimular un modelo de red internacional basado en el auto empoderamiento, descentralización horizontal y relaciones democráticas; 3) reemplazar el "modelo de ayuda" en el que hay flujos unidireccionales de dinero y material de los sindicatos ricos y poderosos a un "modelo solidario" multidireccional, en el que existan flujos de apoyo político, información e ideas; 4) enfocar prioridades hacía actividades directas, visitas y apoyo de las bases y alejarse de declaraciones verbales, conferencias y llamados; y 5) ligar la solidaridad en el extranjero con la acción en casa, combatiendo el racismo, nacionalismo y discriminación de cualquier tipo de forma local.

Una vezanalizada la literatura reciente sobre la colaboración sindical transfronteriza, en la siguiente sección se desarrolla el modelo para analizar su eficacia en la protección de los derechos y condiciones laborales.

\section{Metodología para la construcción de un modelo de análisis de experiencias de colaboración sindical transfronteriza}

A partir de la revisión teórica, en la presente investigación se propone un modelo de análisis para las ocho experiencias de colaboración sindical transfronteriza que serán documentadas en el presente trabajo. En la primera etapa del modelo de análisis de experiencias de colaboración sindical transfronteriza, se construyeron cuatro 
tipologías. Las tipologías son definidas por Peters (1998) como la interacción entre dos o más variables, misma que produce una nueva variable o clasificación. Las tipologías se construyeron tomando en un primer nivel de análisis si se dan de forma voluntaria o bien institucionalizada y en un segundo nivel si son esporádicas o continuas (Tabla 1).

Tabla 1: Tipología de la colaboración sindical transfronteriza

\begin{tabular}{|c|c|c|}
\cline { 2 - 3 } \multicolumn{1}{c|}{} & Voluntaria & Institucionalizada \\
\hline Esporádica & Voluntaria esporádica & Institucionalizada esporádica \\
\hline Continua & Voluntaria continua & Institucionalizada continua \\
\hline
\end{tabular}

Fuente: Elaboración propia.

Una forma de colaboración voluntaria significa que la relación se da de manera informal, por acuerdos verbales o bien por tradición, mientras que la institucionalizada es una colaboración que está normada por tratados, leyes, acuerdos, convenios o reglamentos. Tanto las colaboraciones voluntarias como las institucionalizadas pueden darse de forma esporádica, para tratar un caso en particular o una crisis, como de forma continua, dentro de un plan de colaboración con metas de largo plazo.

En la primera tipología, denominada voluntaria esporádica, se analizará la experiencia de colaboración internacional de un sindicato mexicano, el sme. En la segunda tipología, la voluntaria continua, se analizarán las experiencias de la usAs y de la RSM (Tabla 2).

Tabla 2: Tipología de experiencias de colaboración sindical transfronteriza

\begin{tabular}{|c|c|c|}
\cline { 2 - 4 } \multicolumn{1}{c|}{ Voluntaria } & \multicolumn{1}{c|}{ Institucionalizada } \\
\hline \multirow{2}{*}{ Esporádica } & $\begin{array}{l}\text { - Sindicato Mexicano de } \\
\text { Electricistas (SME). }\end{array}$ & $\begin{array}{l}\text { - Sindicato Nacional de Trabajadores Mineros, } \\
\text { Metalúrgicos, Siderúrgicos y Similares de la } \\
\text { República Mexicana (SNTMMSRM). } \\
\text { - National Administrative Offices (NAO) del } \\
\text { NAALC, TLCAN. }\end{array}$ \\
\hline \multirow{2}{*}{ Continua } & $\begin{array}{l}\text { Sweatshops (USAS). Against } \\
- \text { Red de Solidaridad de la } \\
\text { Maquila (RSM). }\end{array}$ & $\begin{array}{l}\text { Europeos (CSIR). Sindicales Intrarregionales } \\
\text { - Consejos Europeos del Trabajo (CET). } \\
\text { - Acuerdos Marco Internacionales (AMI). }\end{array}$ \\
\hline
\end{tabular}

Fuente: Elaboración propia. 
Respecto de la tercera tipología, de experiencias institucionalizadas esporádicas, se estudió el caso del sntmmsrm y el caso de las National Administrative Offices, instaladas por el Acuerdo de Cooperación Laboral de América del Norte (NAALC), en el marco de Tratado de Libre Comercio de América del Norte (TLCAN) entre México, Estados Unidos y Canadá y el caso de otro sindicato mexicano. Por último, en la cuarta tipología, la institucionalizada continua, se analizaron tres experiencias primordialmente europeas: CSIR, CET y AMI (Tabla 2).

Una vez construidas las tipologías, en una segunda etapa del modelo de análisis se diseñaron categorías taxonómicas, las cuales como señala Sartori (2011) se refieren a clasificaciones o contenedores de datos conceptualmente definidos, que nos permiten analizar un fenómeno que reúne similares características, es decir, que es de la misma clase y diferenciarlo de los que tienen características diferentes. Las experiencias serán analizadas a la luz de estas categorías, compuestas a su vez de variables. Se proponen dos categorías relativas a la intensidad de la colaboración y de la eficacia de la misma, las cuales son presentadas en la Tabla 3. Cada una de esas categorías y variables permiten a su vez interpretar un nivel de graduación de dichas intensidades.

Tabla 3: Categorías para el análisis de experiencias de colaboración sindical transfronteriza

\begin{tabular}{|c|c|c|}
\hline & \multicolumn{2}{|c|}{ Categorías } \\
\hline & Intensidad de la colaboración & Eficacia de la colaboración \\
\hline$\frac{\frac{a}{0}}{\frac{0}{0}}$ & $\begin{array}{l}\text {-Profundidad en la formación de redes } \\
\text { estables de actores. } \\
\text {-Institucionalización de } \\
\text { la colaboración. } \\
\text {-Tipo de colaboración unidireccional o } \\
\text { multidireccional. }\end{array}$ & $\begin{array}{l}\text {-Actividades conjuntas de protección } \\
\text { de intereses, directas e indirectas. } \\
\text {-Capacidad de protección efectiva de } \\
\text { la libertad sindical, la negociación } \\
\text { colectiva, el nivel salarial y las } \\
\text { condiciones laborales. }\end{array}$ \\
\hline
\end{tabular}

Fuente: Elaboración propia. Algunas variables introducidas al modelo fueron analizadas por Kay (2005) y Waterman (citado en Wills, 1998, p. 119).

Para conocer las intensidades de la colaboración de acuerdo al modelo, es importante verificar la profundidad en la formación de redes estables de actores, tomando en cuenta el número y tipo de actores involucrados en la experiencia de colaboración sindical transfronteriza. Asimismo, para calibrar la institucionalización de la colaboración puede verificarse si existen instrumentos que la lleven a un nivel de norma, directriz, acuerdo, reglamento o ley. Para conocer el tipo de colaboración, si es unidireccional o multidireccional, se tomarán en cuenta el tipo de actividades que hace cada uno de los actores y si es que estas generan dependencia o más bien son de apoyo mutuo. 
Para analizar la eficacia de la colaboración, hay que conocer el tipo de actividades conjuntas de protección de intereses, para saber si son directas, es decir, si implican una acción en el terreno de negociación o bien, indirectas, tales como posicionamientos verbales privados o públicos. Para calibrar la capacidad de protección efectiva, se constatará si las acciones anteriores tuvieron impacto positivo sobre variables tales como la libertad sindical, la negociación colectiva, el nivel salarial y las condiciones laborales. Las dos categorías analizadas se dividen según tres niveles, bajo, medio y alto; los cuales, dependen de la intensidad y eficacia lograda por la colaboración de acuerdo con la información disponible para el análisis de cada caso, la cual evidentemente tiene un carácter subjetivo conforme a la interpretación del autor y puede estar sujeta a debate.

A continuación, con este modelo como guía se analizarán las ocho experiencias de colaboración sindical transfronteriza, primero las informales o voluntarias y después las formales o institucionalizadas.

\section{Análisis de las experiencias de colaboración sindical transfronteriza}

\section{Tipología 1. Voluntaria esporádica}

\section{Sindicato Mexicano de Electricistas}

Durante el gobierno de Felipe Calderón Hinojosa (2006-2012) se dieron varios enfrentamientos con los sindicatos. Uno de ellos fue el relacionado con la extinción del organismo público descentralizado, Luz y Fuerza del Centro (LyFC), con lo que se inició un conflicto con el sme, representado por Martín Esparza Flores, mismo que ha sido documentado por Rubio (2016).

Si bien la lucha del sme fue apoyada con acciones internacionales de protesta, estas fueron insuficientes para revertir la extinción así como para atraer la atención del gobierno. Por citar un par de ejemplos, el Global Power Trade Unions Congress organizó protestas frente a las embajadas de México de los países donde tienen operaciones, como Australia e Irlanda y la Unión Danesa de Electricistas envió una misiva a Felipe Calderón (sme, 2013), pero su efecto fue nulo. Más delante, ya en el sexenio de Enrique Peña Nieto (2012-2018), se manifestó apoyo internacional para lograr una salida al conflicto del sme, de parte de la Confederación Nacional Metalúrgica-Central Única de Trabajadores (GNM-CUT) de Brasil, de la Federación Italiana Metal Mecánica, de la Utility Workers Union of America, del Sindicato de Trabajadores Mineros de Rusia y de los Trabajadores Metalúrgicos de Finlandia (Sindicato Mexicano de Electricistas Departamento Cuernavaca, 2013).

En este contexto, de acuerdo con Rubio (2016), en los años 2015 y 2016 se inició una nueva era para el sme, el cual creó una sociedad con la empresa portuguesa MotaEngil, cuyo nombre es Generadora Fénix, que competirá en el mercado eléctrico mayorista de energías limpias, con la operación de varias termoeléctricas y plantas de ciclo combinado en el país (que pertenecieron a la extinta LyFC). El sindicato será socio y a su vez pondrá el capital de trabajo, mientras que la empresa privada aportará la inversión financiera. Mota-Engil tendrá $51 \%$ de las acciones de esta nueva sociedad y el resto de los títulos serán propiedad de LyFC, cooperativa que representa a los más 
de 14000500 trabajadores que no aceptaron su liquidación tras la extinción de LyFC en el 2009 y continúan leales al sme (Rubio, 2016).

Lo anterior no cambia la condición legal de LyFC en lo referente a la extinción de la misma, pero representa una nueva estrategia del SME para reconvertirse en una cooperativa asociada a la empresa portuguesa para buscar ser de nueva cuenta un actor relevante en el sector. Por parte del nuevo gobierno federal, representa una forma distinta de negociar con el SME tras la extinción al permitirle participar de nuevo en la generación eléctrica. Es difícil saber qué tanto de esta nueva relación se facilitó por haber cambiado el partido político en el poder y qué parte por la presión sindical internacional. Quizás el efecto de la presión sindical internacional podría ser más claro de haber estado en el poder el mismo partido y cambiado su postura frente al conflicto a raíz de las muestras de apoyo.

Las pugnas entre el Sindicato Único de Trabajadores Electricistas de la República Mexicana (suterm) y el SME facilitaron la extinción de LyFc (Rubio, 2016). En este caso, si bien el sme contó con apoyo del sindicalismo internacional, como ya se dijo antes, este no fue suficiente para poder revertir la extinción.

De acuerdo al modelo de análisis propuesto, encontramos que estas experiencias de colaboración transfronteriza voluntarias esporádicas muestran una formación de redes en construcción informales. Respecto a las acciones de colaboración entre el SME y los sindicatos internacionales, se limitaron a declaraciones de apoyo a la distancia y su capacidad de protección efectiva fue baja. El tipo de colaboración fue unidireccional, es decir, de los sindicatos extranjeros al SME y no se han documentado casos de acciones similares en dirección contraria.

\section{Tipología 2. Voluntaria continua}

\section{United Students Against Sweatshops}

Una forma emergente de colaboración transfronteriza es la llevada a cabo por la USAs, ${ }^{1}$ la cual es una organización nacional de estudiantes laborales en Estados Unidos fundada en 1997 que lucha por los derechos de los trabajadores, en particular los trabajadores de campus universitarios y trabajadores de la confección de ropa universitaria original con logotipo universitario bajo licencia, en un esquema de consumo responsable, en contra de condiciones de explotación, salarios de pobreza, horas extras forzadas, acoso sexual, falta de libertad sindical, así como violaciones de seguridad y salud laboral.

De acuerdo con su propio sitio en Internet, su estrategia es la siguiente: 1) exigir que sus universidades revelen la ubicación de las fábricas de las marcas que producen ropa universitaria, 2) incentivar a las universidades a adoptar códigos de conducta laboral que establezcan normas mínimas para la producción de prendas de vestir universitaria, y 3) obligar a las escuelas a afiliarse al Worker Rights Consortium (WRC), que es la única entidad de supervisión independiente de ropa.

\footnotetext{
${ }^{1}$ Se puede consultar su portal en http://usas.org/about/national-leadership/
} 
En el año 2001 la usas, en alianza con el Consorcio de los Derechos de los Trabajadores, la Casa Coreana para Solidaridad Internacional, la RSM, el abogado del Frente Auténtico de Trabajadores (FAT) de México, Arturo Alcalde, así como estudiantes de la Universidad Autónoma de Puebla, forzaron a la planta de ropa Kuk Dong, una contratista de Nike en Puebla, a reconocer a un sindicato independiente que beneficiaría las condiciones de empleo de sus trabajadores (Hathaway, 2002, p. 52).

A raíz de las tragedias que causaron cientos de muertes en talleres de ropa en Bangladesh, la usas lanzó la campaña "Terminando con las Trampas Mortales" en el 2013, la cual consistió en obligar a las marcas universitarias bajo licencia a firmar el Acuerdo para la Seguridad en Bangladesh, el cual es un contrato entre compañías de ropa y sindicatos de Bangladesh que requiere que las marcas tengan responsabilidad sobre la seguridad de las fábricas que subcontratan (USAs, s.f.).

Como recuenta Beneyto (2016, p. 62):

El 24 de abril de 2013 se produjo en Bangladesh el derrumbe del edificio Rana Plaza. El colapso de sus ocho plantas, en las que operaban, vulnerando las más elementales normas de seguridad, cinco fábricas textiles y varios talleres auxiliares, trabajando en régimen de subcontratación para 28 grandes multinacionales de la moda, provocó la muerte de 1,138 personas, dejando heridas a otras 2,437, la mayoría mujeres e, incluso, niñas, junto a las que aparecieron, entre los escombros, etiquetas de las marcas de ropa más conocidas del mundo.

La USAS es una forma muy innovadora de protección de las condiciones laborales de los trabajadores en un esquema de consumo responsable. Aunque no es en sí misma un ejemplo de colaboración pura entre sindicatos, sí es un ejemplo de colaboración entre consumidores, otros actores y sindicatos. De acuerdo con el modelo de análisis propuesto, encontramos que la usas muestra que la intensidad de la colaboración entre sindicatos y otros actores es media, pues se está en la fase de formación de redes en maduración, con una institucionalización de la colaboración en proceso principalmente por medio de la firma de acuerdos, con actividades aún del tipo unidireccional.

Respecto de la eficacia de la colaboración, se encontró que mientras que las actividades conjuntas de protección de intereses están relacionadas con la exigencia a las empresas (por verificar las condiciones laborales de la cadena de proveedores) y la presión de organizaciones de la sociedad civil y sindicatos internacionales (por reconocer a sindicatos independientes), se tiene una capacidad de protección efectiva media, sobre todo al apoyar el reconocimiento de sindicatos independientes y verificaciones de condiciones laborales de los trabajadores por parte de las grandes empresas de la industria textil.

\section{Red de Solidaridad de la Maquila}

Otra experiencia de colaboración voluntaria continua tiene que ver con la Red de Solidaridad de la Maquila (RSM), ${ }^{2}$ la cual es una organización de derechos laborales y

\footnotetext{
${ }^{2}$ Se puede consultar su portal en http://www.maquilasolidarity.org
} 
de las mujeres que apoya los esfuerzos de las trabajadoras y trabajadores de la industria del vestido en las cadenas globales de suministros para lograr mejores salarios y condiciones de trabajo y un mayor respeto por sus derechos.

La RSM trabaja principalmente en Centroamérica, México y en Bangladesh, en casos de violaciones a los derechos de las y los trabajadores y en proyectos e iniciativas conjuntas con un enfoque a problemas sistémicos. La RsM cree que las marcas de ropa y las grandes tiendas internacionales comparten la responsabilidad por las condiciones de trabajo en sus fábricas textiles proveedoras y deben ser hechas responsables por las políticas y prácticas que contribuyen a los abusos de los derechos de las y los trabajadores en esas fábricas.

De acuerdo al modelo de análisis propuesto, encontramos que esta experiencia de colaboración transfronteriza al igual que la usAs, con la que también han colaborado, muestra una intensidad de la colaboración media, también en la fase de formación de redes en maduración, con una institucionalización de la colaboración en proceso principalmente por medio de la firma de acuerdos, con actividades aún del tipo unidireccional.

Respecto de la eficacia de la colaboración, se encontró al igual que la usas, que mientras que las actividades conjuntas de protección de intereses están relacionadas con la organización de los trabajadores, la exigencia a las empresas por verificar las condiciones laborales de la cadena de proveedores y la presión de organizaciones de la sociedad civil y sindicatos internacionales por reconocer a sindicatos independientes, se tiene una capacidad de protección efectiva media, sobre todo al apoyar el reconocimiento de sindicatos independientes y verificaciones de condiciones laborales de los trabajadores por parte de las grandes empresas de la industria textil.

\section{Tipología 3. Institucionalizada esporádica}

\section{Sindicato Nacional de Trabajadores Mineros, Metalúrgicos, Siderúrgicos y Similares de la República Mexicana}

Durante el sexenio del expresidente de México, Felipe Calderón Hinojosa (20062012), se dio una persecución contra Napoleón Gómez Urrutia, Secretario General del Sindicato Nacional de Trabajadores Mineros, Metalúrgicos, Siderúrgicos y Similares de la República Mexicana (sNTmMSrm), quien huyó desde el año 2006 a Canadá, por acusaciones de un presunto desfalco contra el patrimonio del sindicato y de los trabajadores, hecho que se dio a conocer tras el diferendo del líder sindical con el gobierno federal y Grupo México por la muerte de 65 mineros en la mina de Pasta de Conchos, en Sabinas, Coahuila, el 19 de febrero del 2006, de la cual Napoleón Gómez Urrutia los hacía corresponsables.

Desde el 2006 y hasta agosto del 2017, el líder minero se ha mantenido en el poder a pesar de este exilio, protegido por el sindicato minero del Congreso del Trabajo de Canadá y haciendo sus asambleas a través de vídeo conferencias, a la par que lucha en tribunales mexicanos para poder volver una vez que no pese ya orden de aprensión alguna en su contra. 
De acuerdo con García (2012, p. 313), en el 2003 Gómez Urrutia afilió al sindicato minero mexicano a la Federación Internacional de Trabajadores de las Industrias Metalúrgicas (FIтіM) y fue nombrado representante de la dirección regional de América Latina de dicha organización en el 2005 y fue incluido en ese mismo año en su comité mundial directivo, realizando viajes y reuniones con sindicatos mineros y metalúrgicos de Argentina, Brasil, Estados Unidos, Canadá y varios países de Europa.

Señala García (2012, p. 313) que en el 2005 se anunció que trabajadores de México y Estados Unidos harían un frente común contra el Grupo Minero México, a quien acusaban de violar las condiciones generales de trabajo, de congelar salarios y disminuir beneficios médicos y pensiones a los trabajadores, por lo que en el 2006 la FITIM presentó una queja en la Organización Internacional del Trabajo (OIT) contra el gobierno mexicano citando violaciones del Convenio 87 de la oIT, relativo a la libertad sindical y la protección del derecho de sindicación.

Más delante, señala García (2012, pp. 313-319) que los United Steelworkers (USW) estadounidenses presentaron cargos por violaciones al NAALC por parte del gobierno de México cuando no reconoció a Napoleón Gómez Urrutia y el presidente de los Steelworkers, Leo Gerard, conminó públicamente a Felipe Calderón para que terminara la interferencia gubernamental negativa en el sindicalismo minero.

Esta colaboración sindical transfronteriza marca la pauta para la defensa futura de los sindicatos ante injerencias de los gobiernos en turno en sus liderazgos y la autonomía de la organización sindical. Utilizando el modelo de análisis propuesto, en este caso las redes con sindicatos internacionales son formales e institucionalizadas al ser parte de una federación internacional de trabajadores mineros. Respecto a las acciones de colaboración, fueron directas, al proteger efectivamente al líder mexicano al darle asilo en Canadá e interponer quejas formales ante la oIt y en el marco del NAALC. El tipo de colaboración fue unidireccional, es decir, de los sindicatos extranjeros a los mexicanos y no se han documentado casos de acciones similares en dirección contraria.

\section{National Administrative Offices}

Nolan (2014) ha analizado los esfuerzos de redes sindicales transfronterizas en el marco del TLCAN. Para Risse et al., citados por Nolan (2014), las redes transnacionales de defensa en este caso tienen tres propósitos: 1) proporcionan información sobre violaciones a los derechos humanos en el Estado involucrado, dado que los derechos laborales son derechos humanos de segunda generación; 2) legitiman los reclamos de los grupos de oposición dentro del Estado, fortaleciendo de esta manera este tipo de reclamos y 3) desafían a aquellos Estados que violan normas para que modifiquen su comportamiento.

Para Carr (1999), algunos ejemplos de colaboración sindical transfronteriza entre México y Estados Unidos se remontan a la época alrededor de la Segunda Guerra Mundial, donde la Confederación de Trabajadores de México (стм) colaboró con el Congreso de Organizaciones Industriales ( $\mathrm{CIO}$ ) para organizar a los trabajadores mexicanos en California.

Autores como Carr (1999), señalan que si bien en la región fronteriza entre México y Estados Unidos ha habido obstáculos importantes para la sindicalización, se han 
dado movimientos como el del Comité de Apoyo Fronterizo Obrero Regional (CAFOR), que en conjunto con el Comité de Apoyo de San Diego han desarrollado programas en formación de salud y seguridad para los trabajadores de las maquiladoras, así como la Alianza para la Justicia en las Maquiladoras, lo que el autor ha denominado "globalización desde abajo".

Según Carr (1999), en el marco del TLCAN se estableció de manera complementaria el NAALC, cuyos principios rectores son: el derecho a negociar colectivamente, de libertad de organización y de huelga, protección laboral para los niños, salarios iguales para hombres y mujeres y protección de los trabajadores inmigrantes, aunque tiene poderes muy limitados para actuar contra las violaciones de los mismos, dado que el TLCAN estipula que cada país tiene libertad sobre sus normas laborales, por lo que utilizar el NAALC para garantizar temas como el reconocimiento de las empresas a los sindicatos independientes en México, ha sido un fracaso.

Para hacer efectivas las controversias laborales presentadas en el marco del NAALC se crearon las NAO. El equivalente a la NAO en Estados Unidos se llama Office of Trade Agreement Implementation (OTAI). Nolan (2014) señala que el proceso seguido ante las NAO es el siguiente:

Al recibir una queja, una NAO primero determina si se debe revisar con mayor profundidad la denuncia. Si la NAO estadunidense o canadiense decide revisar el caso, se convoca a una audiencia pública con las partes interesadas e involucradas en la queja y se analizan los alegatos contenidos en la queja. Después, se corroboran las afirmaciones para determinar si las acciones del Estado, en el caso presentado, fueron consistentes con las leyes laborales nacionales. Por último, la NAo hace público un informe sobre cómo abordar las cuestiones planteadas en el caso. Las oficinas de la NAO pueden sugerir tres formas de abordar los temas incluidos en las quejas con los países que han cometido violaciones. Para violaciones de salud y seguridad laboral se encuentra disponible toda una gama de remedios que incluyen: las consultas ministeriales, la revisión del caso por un panel de expertos en asuntos laborales, el caso puede ser sometido a un proceso formal de solución de controversias, o la aplicación de multas y sanciones comerciales (Nolan, 2014, pp. 123-124).

Entre 1994 y 2012, se presentaron 25 casos ante las NAO, 12 para Estados Unidos y 13 para México. En su mayoría, las quejas sobre México se refieren a cuestiones relacionadas con la libre asociación sindical, mientras que en Estados Unidos están relacionadas con los derechos del migrante y derechos a la negociación colectiva (Nolan, 2014, pp. 125-126). En lo referente a México, la autora señala que las cuestiones de libertad sindical están relacionadas con la renuencia de los sindicatos tradicionales como la Confederación de Trabajadores de México (стм) a dejar avanzar a los sindicatos independientes y perder con ello poder, apoyados por las Juntas de Conciliación y Arbitraje. Desde 1995, México y Estados Unidos han firmado acuerdos sobre el compromiso con la libertad de asociación (casos Sony, Sprint, sutsP, ITAPSA y Han Young). De estos casos, el más representativo es el de ITAPsa, en el cual 75 grupos en Estados Unidos, México y Canadá firmaron una petición sobre la violación del derecho de libre asociación ante las NAO de Estados Unidos y Canadá. Otro caso importante fue el de la empresa Maxi-Switch en Sonora, en el cual el gobierno mexicano actuó reconociendo a un sindicato independiente al que se le había negado el registro 
dada la queja ante la NAO de Estados Unidos. Uno más fue el caso de la empresa Han Young en Tijuana en el cual se tuvo un conflicto de reconocimiento de un sindicato independiente y la Confederación Revolucionaria de Obreros y Campesinos (CROC), en el que el gobierno federal también intervino para evitar controversias en el seno del NAALC. Las acciones anteriores ayudaron además a que se diera un avance en la institucionalización del uso del voto secreto en las elecciones sindicales en México para evitar la intimidación (Nolan, 2014, pp. 127-128).

Kay (2005, p. 740) señala que las controversias presentadas ante las NAO se ven reforzadas por acciones concretas como manifestaciones frente a las oficinas centrales de las empresas en cuestión y acciones presentadas en reuniones de accionistas, como peticiones de firmar códigos corporativos de conducta. Algunas controversias presentadas por el FAT, como el caso de la empresa Echlin, fueron apoyadas por el Canadian Steelworkers of America (cuswa), incluso financieramente, a pesar de que no había trabajadores canadienses involucrados en los casos (Kay, 2005, p. 740).

De acuerdo con Nolan (2014, p. 130), las discusiones en el marco del NAALC influyeron positivamente en el establecimiento de medidas para evitar el uso de las pruebas de embarazo en México, primero en las contrataciones en las industrias maquiladoras y después en cualquier empleo, así como sancionar el trabajo infantil y la discriminación por género y a personas con discapacidad. Así, Nolan (2014, pp. 133-135) señala que desde que comenzó el proceso del NAALC, el gobierno mexicano ha emprendido importantes avances en materia de aplicación de derechos laborales, en una espiral que va desde afuera hacia adentro, es decir, presionado por compromisos en el marco del TLCAN en las NAO, tanto por grupos nacionales como de Estados Unidos y Canadá, por lo que este acuerdo paralelo creó oportunidades para que las redes transnacionales de defensa establecieran en México un camino para mejorar la aplicación de los derechos laborales.

Otro ejemplo de asociación analizada por Carr (1999) que ha prosperado es la Alianza de Organización Estratégica, la cual fue fundada antes del TLCAN, entre el Frente Auténtico de Trabajadores (FAT), ${ }^{3}$ de México, y la United Electrical, Radio and Machine Workers of América (UE) de Estados Unidos. Carr (1999) señala que el objetivo inicial de la alianza consistía en proporcionar conocimientos y dinero para la organización de los trabajadores de las maquiladoras que pertenecían a empresas de Estados Unidos, comenzando con una fábrica de General Electric (GE) en Ciudad Juárez y otra de Honeywell en la ciudad de Chihuahua.

Para Hathaway (1997, pp. 1-30), el FAT fundado en 1960 a partir del grupo Promoción Obrera nacido años antes, en 1958, surgió en la Ciudad de México como un esfuerzo por representar de forma independiente los intereses de los trabajadores frente a la relación corporativista de otros sindicatos aglutinados en el Congreso del Trabajo (CT) con el Partido Revolucionario Institucional (PRI) y tuvo un origen más parecido al de un movimiento social que al de un sindicato, financiado en parte por organizaciones relacionadas con la Iglesia Católica, como el Secretariado Social de México. Sin embargo, se fue alejando de la Iglesia y comenzó a recibir apoyos de otros sindicatos nacionales, europeos y de América del Norte, de ideología socialista y social democrática, con los cuales tenía una similar conciencia de clase, mientras que a su vez, durante los años ochenta el fat proveía de material y apoyo político a trabajadores en Centro América.

\footnotetext{
${ }^{3}$ Su portal se encuentra disponible para consulta en http://www.fatmexico.org.mx
} 
El Fat se alejó de los llamados "sindicatos charros", que trabajaban más por los intereses del partido en el poder y por los propios, cayendo en actos de corrupción. El término "sindicato charro" fue acuñado tras la protección del expresidente Miguel Alemán Velasco al líder ferrocarrilero Jesús Díaz de León por sobre otros líderes que le disputaban el poder. Díaz de León gustaba de usar traje charro en sus labores sindicales, así que ahora se le conoce como "líder charro" a cualquiera que sea manejado por el partido en el poder y se comporte de manera corrupta (Hathaway, 1997, p. 5).

Los principios constitutivos del Fat son: la libertad sindical, democracia sindical, independencia ante los partidos políticos, autonomía sindical ante los gobiernos y los patrones, y la lucha constante por la elevación material y espiritual de la clase trabajadora (Hathaway, 1997, p. 7). En su inicio, el FAT recibió capacitación y algunos recursos de la Latin American Christian Union Confederation (CLASC) y varias de sus reuniones iniciales se daban en iglesias (Hathaway, 1997, pp. 4-7). Los afiliados al FAT se estimaban en 30000 (Kay, 2005, p. 726).

Durante la época de la negociación del TLCAN, algunos sindicatos de Estados Unidos y Canadá con los que el Fat tenía antiguos contactos entre otros, vieron en él un aliado en la lucha anti libre comercio por sus posiciones en contra de la política de abaratamiento de la mano de obra del gobierno mexicano, formándose en abril de 1991 la Red Mexicana contra el TLCAN (REMALC), que convocó en 1991 a sindicatos de los tres países para tratar de influenciar las negociaciones del tratado, haciendo una alianza estratégica con organizaciones como la United Electrical Workers Union (UE), cuyos trabajadores eran amenazados con el despido al mover las operaciones de las empresas donde laboraban a México, por lo que enseguida organizaron a trabajadores de ambos lados de la frontera, como los de las plantas de General Electric (GE) en Ciudad Juárez y Honeywell en Chihuahua (Hathaway, 1997, pp. 22-24). La ue fue fundada en 1936 y sus miembros se estimaban ligeramente por encima de los del FAT, en 35000 (Kay, 2005, p. 718). Antes de 1991 no existían lazos del FAT con la UE o algún otro sindicato de Norteamérica, pero al concretarse las negociaciones del TLCAN los sindicatos reevaluaron sus estrategias, al verlo como una amenaza tangible a las condiciones laborales de la región (Kay, 2005, p. 727).

Según Hathaway (1997, p. 24), la FAT organizó la primera elección sindical con voto secreto y fueron también ellos quienes presentaron la primera queja ante la NAO en el caso de Honeywell con la ayuda de la Ue y los Teamsters, aunque fue desestimada por la falta de experiencia en la documentación de los casos. Más delante, la alianza entre la FAT y la UE logró organizar a trabajadores mexicanos en una pequeña fundidora en Milwaukee, Wisconsin, a los cuales la UE por sí sola había fallado en afiliar, por lo que se envió a un representante de la FAT a explicarles que la UE era un sindicato independiente y no "charro", lo que le dio éxito al registro y ganaron el contrato ante la empresa. Dado que uno de los motivos por los cuales algunas luchas conjuntas iniciales entre el FAT y UE no prosperaron fue la falta de experiencia de los trabajadores en este tipo de ejercicios, ambas organizaciones fundaron en 1996 el Centro de Estudios y Taller Laboral A. C. (CETLAC) para trabajadores en Ciudad Juárez (Hathaway, 1997, p. 25; Kay, 2005, p. 730; uE International Mexican Labor, s.f.). En 1997 la FAT y la UE en conjunto con su contraparte canadiense se unieron en Chicago para compartir información sobre sus contratos y las condiciones laborales con una empresa automotriz en la cual tenían o buscaban contratos colectivos (Hathaway, 1997, p. 25). 
Otra colaboración se dio entre el FAT y la Canadian Steelworkers of America (CUSWA), donde se estableció un fondo de asistencia financiera de emergencia para el Fat en caso de huelgas de hasta cinco años. Así, el fat ha utilizado estrategias de formación de coaliciones para lograr sus objetivos, tanto a nivel nacional, como en el marco del TLCAN y fuera de él (Hathaway, 1997, p. 30).

Otro caso interesante señalado por Carr (1999) es el de Sindicato de Telefonistas de la República Mexicana (strm), que alegó que Sprint Corporation había cerrado sus operaciones en San Francisco y despedido a más de 200 empleados latinos de su subsidiaria de telemarketing en idioma español (llamada La Conexión Familiar), interponiendo una denuncia ante la NAO establecida para cuestiones de arbitraje laboral en el marco del TLCAN. Además, señala que el STRM ha firmado acuerdos con sindicatos canadienses para intercambios de información, programas conjuntos de formación y solidaridad internacional.

Si bien Carr (1999) ve como positivos estos esfuerzos, invita a mantener una mirada crítica respecto de lo que la colaboración sindical transfronteriza puede o no lograr, sobre todo por el carácter asimétrico de los sindicatos de Estados Unidos sobre los mexicanos, a quienes conciben muchas veces como una amenaza, buscando un proteccionismo de su gobierno frente a estos, como el caso de los sindicatos de transportistas en Estados Unidos frente a los choferes mexicanos en el marco del TLCAN.

Para Hathaway (2002, p. 52), la solidaridad internacional hacia los trabajadores mexicanos inició en Estados Unidos y Canadá, cuando los sindicatos trataban de detener a los mexicanos que les quitaban sus trabajos. Es decir, si las fábricas se estaban yendo a México por tener mano de obra barata que no demandaba buenas condiciones laborales, una estrategia es asesorar a los trabajadores mexicanos para poder mejorar esto, lo que en teoría podría hacer que sea relativamente menos rentable para las empresas irse a México en el largo plazo.

Lo anterior, como señala Kay (2005, p. 716) contradice la hipótesis que se tenía previamente a la firma del TLCAN, que auguraba que los sindicatos de Norteamérica competirían por los trabajos manufactureros, resultando por el contrario, una mayor colaboración entre ellos. Más bien, Kay (2005, p. 717) indica que el TLCAN y el NAALC estimularon la relación entre los sindicatos al constituir una nueva estructura de oportunidad política transnacional para la colaboración.

Kay (2005, pp. 718-741) señala que el TLCAN catalizó el transnacionalismo laboral en dos vías: 1) estimuló la movilización política en contra de la firma del tratado, fomentando la colaboración entre sindicatos de los tres países; 2) el NAALC asentó nuevas reglas para establecer quejas contra violaciones a los derechos laborales en América del Norte en una NAO de un país diferente a donde se alega que se violaron los derechos laborales (puede ser la NAO del país de donde es originaria la empresa, pero la queja se pone contra el Estado, no una empresa o persona particular) y obliga a los sindicatos a buscar aliados sindicales en el país donde se interpone la queja, lo que incrementa la solidaridad al enterarse de los problemas que enfrentan los trabajadores de otros países en casos concretos y a profundidad, lo que fomenta la interacción y diseminación de esta información, incrementándose cada vez más el número de sindicatos que participan en las quejas ante las NAO, pues al principio lo hacían entre dos sindicatos y ahora entre más de 50 organizaciones. Así, el NAALC catalizó relaciones sindicales transfronterizas que antes no existían. 
Hathaway (2002, p. 52) señala que el FAT es frecuentemente usado como una herramienta de los sindicatos extranjeros que pretenden prevenir la reubicación de las empresas y de sus trabajos en México. Indica que un efecto de esto es que las empresas prefieran localizarse en países como Guatemala, El Salvador, Indonesia o China, en busca de mano de obra más barata, por lo que a largo plazo el objetivo debe ser cambiar la política laboral internacional, a través de sindicatos democráticos fuertes con un gran sentido de solidaridad internacional (Hathaway, 2002, p. 54).

Carr (1999) indica que hay que estar atentos de los peligros, sobre todo ante las crisis y desafíos enfrentados por las naciones que pueden proporcionar oportunidades creativas a los sujetos históricos en conflicto. Carr agrega que:

El libre comercio puede proporcionar espacios para desafiar y rectificar las acciones arbitrarias del Estado siempre y cuando, desde luego, se viesen acompañados de modificaciones radicales de la legislación laboral federal de México, con el fin de acabar con los poderes del Estado que aplasta a los sindicatos al negarles reconocimiento, o que declara las huelgas no existentes y decreta sindicatos únicos en las empresas, lo cual ha generado luchas que aún no han acabado (Carr, 1999, p. 13).

Uno de estos peligros señalados por Carr (1999) puede ser la llegada al poder del presidente de Estados Unidos de América, Donald Trump, que ha manifestado actitudes proteccionistas y exigido a empresas de su país no llevarse los empleos a México, lo que podría crear y reavivar pugnas entre los sindicatos de ambos países.

Analizando esta experiencia de las NAO a la luz del modelo de análisis propuesto, encontramos que aquellas redes de que se hicieron entre los sindicatos norteamericanos previas a la firma del TLCAN sirvieron como preámbulo para presentar denuncias laborales ante las NAO del NAALC, que exige que se cuente con un aliado en el país donde se presente la denuncia y que debe ser diferente al país donde se presenta el problema que la origina. Eso ha apoyado la formación de redes de colaboración estables y en lugar de que el TLCAN ocasionara solo fricciones entre sindicatos, como sucedió con el caso del sector transporte, permitió una mayor colaboración entre ellos, al menos por más de dos décadas antes de la llegada de la era Trump.

Respecto de las actividades conjuntas de protección de intereses, estas han ido en incremento y han sido acciones sobre todo directas, reforzadas en algunos casos con acciones indirectas, como manifestaciones de apoyo o protestas internacionales. El tipo de colaboración ha sido multidireccional, presentándose apoyo entre aliados en casos de violaciones de los Estados en materia laboral en diversas NAO, sobre todo en México y Estados Unidos y, en menor medida, de Canadá.

La colaboración está institucionalizada de acuerdo con las reglas del NAALC y además, se ha presentado una curva de aprendizaje positiva en la presentación de denuncias y documentación de los casos a más de veinte años de la entrada en vigor del TLCAN, lo que ha permitido tener mayor capacidad de protección efectiva, sobre todo en lo referente a la defensa de la libertad y autonomía sindical. 


\section{Tipología 4. Institucionalizada continua}

\section{Consejos Sindicales Interregionales Europeos}

Para Streeck and Schmitter, citados por Sadler (2000, p. 141), la construcción de un mercado europeo único condujo a un quiebre de los sistemas nacionales corporativistas de relaciones industriales.

Con la creación de la Comunidad Económica Europea, en 1958 se crea el Secretariado Europeo de Sindicatos, que después se convirtió en la Confederación Europea de Sindicatos Libres en 1969 y, más delante en 1973, en la Confederación Europea de Sindicatos, CES (Sadler, 2000, p. 143).

La CES agrupa a 81 organizaciones de 36 países europeos y a 12 federaciones sindicales europeas, con un total de 60 millones de afiliados (Eurored, s.f.). La CES tiene como objetivo en su plan de acción alentar, favorecer y apoyar iniciativas de colaboración entre sindicatos sectoriales en áreas donde las condiciones económicas, territoriales, monetarias y sociales sean similares (Consejos Sindicales InterregionalesConfederación Europea de Sindicatos [CSIR-CEs], 2009).

Esta confederación coordina las actividades de los CSIR, que organizan la colaboración sindical a nivel transfronterizo, incluyendo a sindicatos de varias ciudades de dos o tres países, siendo actualmente 45 consejos, el primero de ellos fundado en 1976 (CSIR-CES, 2009; European Trade Union Confederation [ETUC], 2013; Hammer, 2010).

Estos CSIR se han planteado como meta implementar actividades de colaboración estrictas entre sindicatos de diferentes países a fin de influir en las prácticas vigentes en materia de negociación colectiva, de tal forma que cuando una empresa se deslocalice entre diversas fronteras encuentre un solo sindicato y una sola estrategia reivindicativa para negociar a nivel transfronterizo (CSIR-CES, 2009).

Como parte de este esfuerzo, durante el 2009 se organizaron seminarios de intercambio de información entre los siguientes siete csir: Italia-Eslovenia, EspañaPortugal, Italia-Suiza, Alemania-Polonia, Italia-Croacia, Alemania-Polonia-República Checa y, España-Portugal. Como conclusión de los mismos, se señaló que "es preciso subsanar la asimetría que caracteriza a los poderes existentes, es decir, la libertad sin fronteras de la que disponen las empresas, mientras que los poderes de negociación colectiva permanecen bloqueados en el ámbito nacional" (CSIR-CES, 2009, p. 48).

A pesar de haber surgido a mediados de los años setenta, Alves y Rego (2012, p. 414) señalan que los CSIR continúan siendo una "caja negra" en los estudios laborales. Recientemente las experiencias de los CSIR han sido abordadas por Alves y Rego (2012), que han analizado los cuatro CSIR de Galicia-Norte y Portugal, mientras que Hammer (2010) hizo lo propio con el csir de West Pannonia, situado en la frontera entre Austria y Hungría.

Para Hammer (2010), los CSIR fueron establecidos como iniciativas bottom-up o desde abajo, para hacer frente a problemas y asimetrías del mercado laboral y las relaciones industriales en regiones adjuntas, usualmente a nivel subnacional, sobre todo relacionadas con los niveles salariales, doble imposición y condiciones laborales, lo cual es muy importante para aquellos casos en los que existen sindicatos débiles y fragmentados, como en los nuevos Estados miembros de la Unión Europea y donde 
existen trabajadores que se emplean entre estas fronteras, los cuales frecuentemente enfrentan diferentes condiciones laborales y presiones por parte de las empresas para que estas empeoren, situaciones denominadas como dumping social, las que crean a su vez incentivos para la colaboración entre sindicatos.

Según Hammer (2010), los CSIR han mostrado un desarrollo positivo desde su creación en 1976 y han venido a llenar un vacío en las instituciones políticas europeas, tanto en temas de políticas laborales, económicas y sociales. Para Hammer (2010), la colaboración a través de los csir se enfoca en compartir información sobre regulaciones de empleo, asesoría legal, apoyo, representación, capacitación en cuestiones de organización sindical y negociación, así como representación política cara a cara con autoridades regionales del trabajo, a quienes brindan información sobre empresas que incumplen con la legislación laboral y son consultadas sobre diversas políticas de empleo, lo que convierte a los CSIR en actores sociales relevantes. Al respecto, Alves y Rego (2012, p. 418) señalan que los CSIR establecen redes interregionales con las asociaciones de empleados, servicios públicos e instituciones de educación y capacitación, no solo entre sindicatos.

De acuerdo con Alves y Rego (2012, pp. 415-417), el proceso que generalmente siguen los CSIR para su formación es el siguiente: 1) acercamiento informal entre sindicalistas regionales; 2) firma de declaración conjunta para cooperar con metas programáticas; 3) formalización de estructura interna de los CSIR, que se compone de dos cuerpos principales: la conferencia conjunta, formada por igual número de delegados de cada confederación de sindicatos cuyo presidente y el comité ejecutivo rotan cada año, teniendo el primero el más alto nivel estatutario, donde se define la estrategia y se eligen a los miembros del comité ejecutivo. Noack, citado por Alves y Rego (2012, p. 416), señala que la mayoría de las decisiones en los CSIR son tomadas por consenso y en algunos casos con mayoría calificada de tres cuartos.

Alves y Rego (2012, pp. 416-418) han encontrado algunos obstáculos para el funcionamiento adecuado de los CSIR. Indican que la mayoría de las veces el equipo de los CSIR está formado por el mismo equipo del presidente en turno, lo que dificulta la continuidad de los esfuerzos, por lo que algunos CSIR han trabajado procurando designar personal exclusivo que no cambie con la presidencia, lo que generalmente no es posible por cuestiones presupuestales. Otro obstáculo tiene que ver con la diferencia de idiomas y por último, señalan el incremento de formas no estándares de empleo como el empleo temporal, subcontratación y trabajo ilegal.

Así, de acuerdo al modelo de análisis propuesto para la presente investigación, los CSIR han incrementado constantemente la formación de redes estables entre sindicatos de diferentes regiones en Europa desde el primer csir creado en 1976 hasta los 45 existentes actualmente, dando paso a una institucionalización mayor de este tipo de colaboración surgida como una iniciativa bottom-up o desde abajo, la cual se da de forma multidireccional entre los diferentes sindicatos integrantes, los cuales comparten problemas muchas veces comunes dada su cercanía geográfica, que además facilita la colaboración.

Las actividades conjuntas de protección de intereses son primordialmente del tipo directas, tales como: compartir información sobre regulaciones de empleo, asesoría legal, apoyo, representación, capacitación en cuestiones de organización sindical y negociación, así como representación política cara a cara con autoridades regionales del trabajo, a quienes brindan información sobre empresas que incumplen con la legislación laboral y son consultadas sobre diversas políticas de empleo. De este modo, 
la capacidad de protección efectiva ante los fenómenos de deslocalización de las empresas y del dumping social se da primordialmente mediante el fortalecimiento de capacidades sindicales.

\section{Consejos Europeos del Trabajo}

Según el European Trade Union Confederation (ETUC, 2008), en 1994 se aprobó una directriz denominada Consejos Europeos del Trabajo (CET), que aplica a todas las compañías del continente con 1000 o más trabajadores y que tienen al menos 150 empleados en cada uno de los estados miembros donde tienen operaciones, la cual las obliga a establecer estos CET para reunir a los sindicatos donde operan para reunirse con los administradores de la empresa y brindarles sus puntos de vista sobre las estrategias y decisiones que afectan a la empresa y a los trabajadores. Previo a esta directriz, que entró en vigor en septiembre de 1996, los acuerdos tuvieron un carácter de "voluntarios" y están exentos de algunos requerimientos posteriores a la misma (Spiegelaere y Jagodzinski, 2015, p. 13).

El ETUC (2008) estima que de 2264 compañías que caen bajo esta directriz, 34\% cuentan con un CET y entre las multinacionales que emplean más de 10000 personas o más $61 \%$ cuentan con ellos. ETUC (2008) señala que las compañías que no han podido establecer un CET tienden a ser empresas pequeñas, con un bajo nivel de organización sindical, con administraciones hostiles a involucrar trabajadores en los procesos de decisión o compañías que han experimentado drásticos procesos de reestructuración en los últimos años (ETUC, 2008).

ETUC (2008) señala que hay pocos castigos para las compañías que no cumplen con estas directrices, por lo que es necesario establecer sanciones disuasivas, tales como invalidar legalmente decisiones que sean llevadas a cabo por las compañías sin involucrar a los trabajadores en dichas decisiones o bien hacer compensaciones a los mismos. Esto es importante para evitar casos como los de Renault en Vilvoorde, Bélgica o Nokia en Finlandia, que hicieron grandes restructuraciones sin consultar a los trabajadores, desafiando el espíritu de esta directriz.

La mayoría de los CET se reúnen una vez al año y su estructura generalmente sigue dos modelos: 1) solo representantes de los trabajadores o 2) representación conjunta de los trabajadores y la administración eTUC (2008). Sadler (2000, p. 147) señala que hay que tomar en cuenta varias cuestiones acerca de los CET: 1) existen preocupaciones de que puedan erosionar estándares actuales de representación de los trabajadores; 2) pueden significar más una herramienta administrativa, que pretenda crear sentido de pertenencia de los trabajadores con la empresa sin necesariamente significar ventajas obvias para los trabajadores. Lecher y Rüb, citados por Sadler (2000, p. 147), señalan que muchas ocasiones la información brindada a los representantes de los trabajadores es solo oral y las consultas no son llevadas a cabo seriamente y solo se usan para legitimar decisiones previamente llevadas a cabo por las empresas.

Sin embargo, para Sadler (2000, p. 148) los CET son importantes porque abren nuevos mecanismos que trascienden versiones previas de las relaciones entre el capital y el trabajo, llegando más allá del ámbito nacional y las industrias. Según Spiegelaere y Jagodzinski (2015), hasta junio del 2015 se contabilizaron 1071 CET activos, de los cuales 131, es decir, 12.2\% fueron establecidos del 2010 al 2015, mientras que 
$464(43.3 \%)$ fueron instituidos entre el año 2000 y el 2009 y el resto entre 1985 y 1999. Por número de trabajadores, $32 \%$ de los acuerdos pertenecen a empresas de más de 10000 trabajadores, $15 \%$ a empresas con entre 5000 y menos de 10000 trabajadores, $35 \%$ menos de 5000 trabajadores y el restante $19 \%$ tiene un número de trabajadores desconocido. Respecto de la presencia que tienen las multinacionales que han firmado acuerdos, $42 \%$ de ellas tienen actividades en más de 10 países, $30 \%$ en 5 a 10 países y $18 \%$ en menos de 5 países, mientras que el porcentaje restante se desconoce. Spiegelaere y Jagodzinski (2015, p. 14) señalan que si bien uno de cada dos acuerdos de los CET tienen carácter de indefinido, pueden renegociarse para mejorar los derechos existentes.

Así, retomando el modelo de análisis propuesto en la presente investigación, vemos que la intensidad de la colaboración es relativa, pues los CET generan redes estables de actores con una institucionalización de la colaboración desde la creación del primer consejo hace ya más de dos décadas, sin embargo, el tipo de colaboración que se da es entre grupos de trabajadores de la misma empresa en diversos Estados miembros, pero no se incluyen en esas redes estables a otros sindicatos fuera de la empresa empleadora ni organizaciones de la sociedad civil, lo que limita su capacidad de obtener un apoyo mayor en caso de ser necesario, así como de fortalecer sus capacidades vía asesoría, capacitación y acceso a mejores prácticas.

Referente a la categoría de eficacia de la colaboración, esta es limitada, pues si bien los CET representan un mecanismo transnacional de voz y representación de los trabajadores, las consultas que se hacen a los mismos por parte de las empresas multinacionales carecen de formalidad, sin proporcionar información sólida que permita tener una opinión informada sobre asuntos torales, por lo que muchas veces estas consultas son vistas solo como una táctica para legitimar decisiones previamente tomadas por la administración. Además, existen pocos castigos para las compañías que no cumplen con las directrices estipuladas en los CET, lo que mina su eficacia.

\section{Acuerdos Marco Internacionales}

Según Papadakis (2011), los AMI entre empresas multinacionales y Federaciones Sindicales Internacionales (FSI) son instrumentos que regulan las condiciones laborales y las relaciones de trabajo en el seno de las empresas multinacionales y a lo largo de todas sus cadenas mundiales de valor. Para Hadwiger (2016), en los AMI, las empresas acuerdan respetar los derechos de los trabajadores y promover el trabajo decente o no precario en todo el mundo tanto en sus filiales como en toda su cadena mundial de suministro.

Papadakis (2011) señala que los AMI fortalecen las capacidades gremiales al permitir la libertad sindical y la negociación colectiva, lo que lleva a tener relaciones laborales más democráticas y mejorar los derechos fundamentales en el trabajo de las cadenas mundiales de valor, además de ser el punto de partida de otras iniciativas en el ámbito de la organización sindical transfronteriza.

Beneyto (2016, p. 78) apunta que el primer Ami se firmó en 1988 entre la Unión Internacional de Trabajadores de la Alimentación (UITA) y la multinacional Danone, hasta alcanzar los 173 acuerdos suscritos hasta el momento. Otro AMI importante fue el firmado como convenio colectivo internacional del sector marítimo, entre el 
Comité Marítimo Internacional de Empleadores y la Federación Internacional de los Trabajadores del Transporte (Papadakis, 2011). Según Hadwiger (2016, p. 7), una comparación entre los AMI más antiguos y los más recientes muestra que su contenido y aplicación han evolucionado en los últimos 15 años, ya que las Federaciones Sindicales Internacionales han revisado su estrategia y ahora los acuerdos conllevan procedimientos más sólidos de aplicación, supervisión y resolución de conflictos, además de que facilitan la sindicalización, en lugar de limitarse a aceptarla.

La distribución porcentual territorial de las 173 AMI existentes, según la residencia de la empresa matriz, es el siguiente: Europa 81.5\%; América 11\%; Asia 4.1\%; África 1.7\%; y Oceanía 1.7\% (Beneyto, 2016, p. 79). Así, vemos que el esfuerzo se ha dado sobre todo a nivel europeo, pero ha comenzado a extenderse a otros continentes.

Para Beneyto (2016, pp. 78-80), si bien los AMI carecen de efectos normativos y exigibilidad jurídica, por la inexistencia de la correspondiente norma imperativa de ámbito global, estamos ante la emergencia de un marco de relaciones laborales para la globalización. Según Hadwiger (2016, p. 6), aproximadamente $80 \%$ de los AMI contienen una referencia a la cadena mundial de suministro y alrededor de $30 \%$ consideran el respeto de las disposiciones de los acuerdos como un criterio para establecer y proseguir las relaciones comerciales con los proveedores y subcontratistas.

Además de la referencia a las normas fundamentales de trabajo, los AmI suelen incluir compromisos en materia de información, formación, participación y monitoreo del cumplimiento de los acuerdos en toda la cadena productiva (Beneyto, 2016, p. 80). Para hacer cumplir los acuerdos, Hadwiger (2016, pp. 6-7), señala que los AMI recientes suelen establecer reuniones de consulta continuas y alguna forma de examen global del acuerdo, incluidas visitas en el terreno a las filiales y los proveedores.

Para Beneyto (2016, p. 81), el empoderamiento de las organizaciones de base y de los trabajadores a lo largo de toda la cadena de producción es un reto, por la debilidad sindical, la hostilidad empresarial y la escasa cobertura institucional, lo que representa uno de los principales riesgos de este modelo de colaboración. De acuerdo con Hadwiger (2016, p. 7):

Los resultados de un análisis de 29 estudios de caso sobre la aplicación de los AMI revela el impacto limitado que han tenido en general en los proveedores y subcontratistas en los últimos años, ya que la supervisión de los acuerdos puede plantear desafíos particulares en las fábricas y en otras localizaciones de los proveedores y subcontratistas que no están sindicalizados.

Para hacer frente a lo anterior, Hadwiger (2016, p. 8), recomienda: 1) reforzar la participación de los agentes locales en los procesos de los AMI, desde su inicio hasta su aplicación, pasando por las negociaciones; 2) que proveedores y subcontratistas de las multinacionales firmen conjuntamente el acuerdo y 3) fortalecer los mecanismos de resolución de conflictos con procedimientos de mediación o arbitraje e ir más allá de compromisos voluntarios.

De acuerdo al modelo de análisis propuesto en lo referente a la categoría de intensidad de la colaboración, los AMI han generado en sus casi tres décadas de existir redes estables de colaboración sindical entre las cadenas mundiales de valor en las actividades económicas donde operan. Sobre el tipo de colaboración, si bien es multidireccional, necesita fortalecer el papel de los sindicatos locales en todos los aspectos del acuerdo, pues su operación es de tipo top-down o de arriba hacia abajo. 
Sobre la categoría de la eficacia de la colaboración esta se da primordialmente de forma directa, en cuestiones como información, formación, participación y monitoreo del cumplimiento de los acuerdos en toda la cadena productiva, lo que fortalece las capacidades gremiales al permitir la libertad sindical y la negociación colectiva. Si bien se hacen visitas de monitoreo en filiales y con proveedores, para que las acciones sean efectivas, existen retos como el empoderamiento de las organizaciones de base y de los trabajadores a lo largo de toda la cadena de producción dada la debilidad sindical y la hostilidad empresarial, lo que limita el impacto en los proveedores y subcontratistas.

\section{Conclusiones}

Se propusieron cuatro tipologías de colaboración sindical transfronteriza que permitieron analizar los ocho casos empíricos a partir del modelo teórico creado. En la Tabla 4 se hace una graduación de cada una de las categorías analizadas, de acuerdo con los niveles bajo, medio y alto, que dependen de la intensidad y eficacia lograda por la colaboración, según la información disponible para el análisis de cada caso presentado en esta investigación, la cual evidentemente tiene un carácter subjetivo conforme a la interpretación del autor y está sujeta a debate.

Tabla 4: Intensidad y eficacia de la colaboración sindical transfronteriza

\begin{tabular}{|c|c|c|c|}
\hline \multirow[b]{2}{*}{ Tipología } & \multirow[b]{2}{*}{ Caso } & \multicolumn{2}{|c|}{ Categorías } \\
\hline & & $\begin{array}{l}\text { Intensidad de la } \\
\text { colaboración }\end{array}$ & $\begin{array}{l}\text { Eficacia de la } \\
\text { colaboración }\end{array}$ \\
\hline $\begin{array}{l}\text { Voluntaria } \\
\text { esporádica }\end{array}$ & SME & Baja & Baja \\
\hline \multirow{2}{*}{$\begin{array}{l}\text { Voluntaria } \\
\text { continua }\end{array}$} & USAS & Media & Media \\
\hline & RSM & Media & Media \\
\hline \multirow{2}{*}{$\begin{array}{l}\text { Institucional } \\
\text { esporádica }\end{array}$} & SNTMMSRM & Media & Alta \\
\hline & NAO & Alta & Alta \\
\hline \multirow{3}{*}{$\begin{array}{l}\text { Institucional } \\
\text { continua }\end{array}$} & CSIR & Alta & Alta \\
\hline & CET & Media & Media \\
\hline & AMI & Media & Media \\
\hline
\end{tabular}

Fuente: Elaboración propia. 
Se analizó primero la tipología de colaboración voluntaria esporádica mediante el caso del sme, en el que las pugnas con el suterm facilitaron la extinción de LyFC por parte del gobierno de Felipe Calderón. En este caso, si bien el sme contó con apoyo posterior del sindicalismo internacional, dichas acciones fueron solo indirectas, limitándose a cartas y declaraciones de apoyo a la distancia y no fueron suficientes para poder revertir la extinción. De acuerdo al modelo de análisis propuesto, encontramos que esta experiencia de colaboración transfronteriza voluntaria esporádica muestra una formación de redes en construcción de tipo informal con una muy baja capacidad de protección efectiva y acciones unidireccionales de los sindicatos del extranjero hacía el sme.

En lo que respecta a las experiencias de colaboraciones voluntarias continuas, tales como la USAS y la RSM, la intensidad de la colaboración es media, pues se encuentran en la fase de una formación de redes, con una institucionalización de la colaboración en proceso por medio de la firma de acuerdos y con actividades aún de tipo unidireccional. Respecto a la eficacia de la colaboración, se encontró que mientras que las actividades conjuntas de protección de intereses están relacionadas con la organización de los trabajadores, la exigencia a las empresas por verificar las condiciones laborales de la cadena de proveedores y la presión de organizaciones de la sociedad civil y sindicatos internacionales por reconocer a sindicatos independientes, se tiene una capacidad de protección efectiva media, sobre todo con el logro de apoyar el reconocimiento de sindicatos independientes y la verificaciones de condiciones laborales de los trabajadores por parte de las grandes empresas de la industria textil.

Sobre las experiencias de colaboraciones institucionalizadas de colaboración sindical transfronteriza, se analizaron primero las esporádicas, como el SNTMMSRM y las NAO, establecidas en el marco del NAALC, paralelo al TLCAN. En el caso del SNTMMSRM, se encontró que Napoleón Gómez Urrutia, Secretario General del sindicato, fue muy hábil al construir relaciones con la Fiтiм y el sindicato minero del Congreso del Trabajo de Canadá, lo que le permitió obtener protección cuando comenzó la persecución de parte del expresidente Calderón, de la cual goza hasta el momento, por lo que la capacidad de la colaboración sindical transfronteriza ha sido muy efectiva en este caso.

En este caso del sindicato minero, las redes tienden a ser formales al ser parte de una federación internacional de trabajadores mineros. Con respecto a las acciones de colaboración, fueron directas, al proteger efectivamente al líder mexicano al darle asilo en Canadá. El tipo de colaboración fue unidireccional, es decir, de los sindicatos extranjeros a los mexicanos y no se han documentado casos de acciones similares en dirección contraria de tal magnitud. La institucionalización de la colaboración es media por la afiliación a la federación internacional y su capacidad de protección efectiva alta, en los casos tanto del líder como de la libertad sindical en general.

La segunda experiencia de esta tipología fue la de las NAO. Analizando las NAO a la luz del modelo de análisis propuesto, encontramos que aquellas redes de que se hicieron entre los sindicatos norteamericanos previas a la firma del TLCAN sirvieron como preámbulo para presentar denuncias laborales ante el NAALC, que exige que se cuente con un aliado en el país donde se presente la denuncia y que debe ser diferente al país donde se presenta el problema que la origina. Eso ha apoyado la formación de redes de colaboración estables y en lugar de que el TLCAN ocasionara solo fricciones entre sindicatos, como sucedió con el caso del sector transporte, permitió una mayor colaboración entre ellos. 
De las actividades conjuntas de protección de intereses, estas han ido en incremento y han sido acciones sobre todo directas, reforzadas en algunos casos con acciones indirectas, como manifestaciones de apoyo o protestas internacionales. El tipo de colaboración ha sido multidireccional, presentándose apoyo entre aliados en casos de violaciones de los Estados en materia laboral en diversas NAO, pero sobre todo en México y Estados Unidos y en menos medida de Canadá. La colaboración está institucionalizada de acuerdo con las reglas del NAALC y además, se ha presentado una curva de aprendizaje positiva en la presentación de denuncias y documentación de los casos a más de veinte años de la entrada en vigor del TLCAN, lo que ha permitido tener mayor capacidad de protección efectiva, sobre todo en lo referente a la defensa de la libertad y autonomía sindical. Un riesgo futuro para estas colaboraciones es la llegada al poder del presidente de Estados Unidos de América, Donald Trump, que ha manifestado actitudes proteccionistas y exigido a empresas de su país no llevarse los empleos a México, lo que podría crear y reavivar pugnas entre los sindicatos de ambos países.

Referente a la última tipología, de colaboración sindical institucionalizada continua, se analizaron los csir, los cuales han incrementado constantemente la formación de redes estables entre sindicatos de diferentes regiones en Europa desde el primer consejo creado en 1976 hasta los 45 existentes actualmente, dando paso a una institucionalización mayor de este tipo de colaboración surgida como una iniciativa bottom-up o desde abajo, la cual se da de forma multidireccional entre los diferentes sindicatos integrantes, los cuales comparten problemas muchas veces comunes dada su cercanía geográfica, que además facilita la colaboración.

Las actividades conjuntas de protección de intereses de los CSIR son primordialmente directas, tales como compartir información sobre regulaciones de empleo, asesoría legal, apoyo, representación, capacitación en cuestiones de organización sindical y negociación, así como representación política cara a cara con autoridades regionales del trabajo, a quienes brindan información sobre empresas que incumplen con la legislación laboral y son consultadas sobre diversas políticas de empleo. Así, la capacidad de protección efectiva ante los fenómenos de deslocalización de las empresas y el dumping social se da primordialmente mediante el fortalecimiento de capacidades sindicales.

La siguiente experiencia analizada fue la de los CET, que de acuerdo al modelo de análisis propuesto en la presente investigación tiene una intensidad de colaboración media, pues generan redes estables de actores con una institucionalización de la colaboración desde la creación del primer consejo hace ya más de dos décadas, sin embargo, el tipo de colaboración que se da es entre grupos de trabajadores de la misma empresa en diversos Estados miembros, pero no se incluyen en esas redes estables a otros sindicatos fuera de la empresa empleadora ni organizaciones de la sociedad civil, lo que limita su capacidad de obtener un apoyo mayor en caso de ser necesario, así como de fortalecer sus capacidades vía asesoría y capacitación.

Sobre la categoría de eficacia de la colaboración esta es limitada, pues si bien los CET representan un mecanismo transnacional de voz y representación de los trabajadores, las consultas que se hacen a los mismos por parte de las empresas multinacionales son muy informales, sin proporcionar información sólida que permita tener una opinión informada sobre asuntos torales, por lo que muchas veces estas consultas son vistas solo como una táctica para legitimar decisiones previamente tomadas por la administración. Además, existen pocos castigos para las compañías que no cumplen con las directrices estipuladas en los CET, lo que mina su eficacia. 
Finalmente, se analizaron los AMI, que en sus casi tres décadas de existir han generado redes estables de colaboración sindical en las cadenas mundiales de valor dentro de las actividades económicas donde operan. Sobre el tipo de colaboración, si bien es multidireccional, necesita fortalecer el papel de los sindicatos locales en todos los aspectos del acuerdo, pues su operación es de tipo top-down o de arriba hacia abajo. Sobre la eficacia de la colaboración de los Ami esta es media; se da primordialmente de forma directa, en cuestiones como información, formación, participación y monitoreo del cumplimiento de los acuerdos en toda la cadena productiva, lo que fortalece las capacidades gremiales al permitir la libertad sindical y la negociación colectiva. Aunque se hacen visitas de monitoreo en filiales y con proveedores, para que las acciones sean efectivas, existen retos como el empoderamiento de las organizaciones de base y de los trabajadores a lo largo de toda la cadena de producción dada la debilidad sindical y la hostilidad empresarial, lo que limita el impacto en los proveedores y subcontratistas.

Se considera que la colaboración voluntaria e institucionalizada no deben ser vistas como excluyentes, sino consideradas complementarias, pues unas pueden reforzar a otras, como en el caso de las acciones que se realizan para potenciar el efecto de las NAO.

Se encontró que más allá de que el libre comercio cause siempre una pugna entre los sindicatos de diversos países, la colaboración sindical transfronteriza se presenta como una estrategia factible y eficaz para enfrentar los efectos adversos de la globalización sobre las condiciones laborales, derivadas de las asimetrías entre el poder de las multinacionales y su capacidad de deslocalización, sobre la fragmentación de las organizaciones de trabajadores a través del mundo y las tendencias al dumping social, que originan un círculo vicioso en el afán de atraer inversión extranjera.

El modelo propuesto resultó adecuado para analizar la intensidad y la eficacia de la colaboración sindical transfronteriza en los ocho casos analizados de acuerdo con las cuatro tipologías construidas. Se espera que este modelo pueda servir de guía para un análisis y evaluación más profunda de estas y otras experiencias sindicales en contextos específicos.

\section{Referencias}

Alves, P., y Rego, R. (12-15 de septiembre de 2012). The Interregional Trade Union Councils (IRTUC) and the Cross Border Workers: the Case of the Galicia Norte de Portugal irtuc. En I. M. Pires (Comp.) Borders and Borderlands: Today's Challenges and Tomorrow's Prospects. Proceedings of the Association for Borderlands Studies Lisbon Conference, (pp. 413-428). Lisboa, Portugal: Centro de Estudios Geográficos. Recuperado de https://dspace.uevora.pt/rdpc/bitstream/10174/10879/4/ Borders\%20and\%20Borderlands.pdf

Beneyto, P. (2016). Trabajo y sindicalismo en la globalización. Revista Española de Sociología, 25(1), 61-87. Recuperado de www.fes-sociologia.com/files/journal/25/3/article.pdf

Brown, J. W. (1928). The International Trade Union Movement. Journal of the Royal Institute of International Affairs, 7(1), 29-41. Recuperado de http://www.jstor.org/stable/3014867

Carr, B. (1999). La globalización desde abajo: el internacionalismo sindical en el marco del nafta. Revista Internacional de Ciencias Sociales, (159). Recuperado de http://www.ub.edu/prometheus21/articulos/nautas/17.pdf 
Castel, R. (2002). Las metamorfosis de la cuestión social. Una crónica del asalariado. Argentina: Editorial Paidós.

Consejos Sindicales Interregionales, Confederación Europea de Sindicatos (CSIRCES). (2009). Negociaciones Colectivas. Cooperación Transfronteriza. Recuperado de: http://www.eurodetachement-travail.eu/datas/files/EUR/pdf_Brochure_ CSIR_ES-3[1].pdf

European Trade Union Confederation (ETUC). (2008). European Works Councils (EWCS). Recuperado de https:/ / www.etuc.org/european-works-councils-ewcs

European Trade Union Confederation (ETUC). (2013). Contribución de los CSIR a la realización de los objetivos prioritarios y el programa de trabajo de la CES en materia de coordinación de la negociación colectiva. Recuperado de https://www.etuc.org/IMG/ pdf/Contribution_IRTUC_SP.pdf

Eurored. (s.f.). CES. Descripción. Recuperado de http://eurored.ccoo.es/eurored/ CES._Descripcion

García, A. (2012). Indicadores de trabajo decente y características de organizaciones laborales del sector minero-metalúrgico en México. Revista Ide@s COCYTEG, 7(81). pp. 300- 322. Recuperado de http://www.concyteg.gob.mx/ideasConcyteg/Archivos/81_3_GARCIA.pdf

Hadwiger, F. (2016). Acuerdos Marco Internacionales. Lograr el trabajo decente en las cadenas mundiales de suministro (Documento de referencia). Recuperado de http://www. ilo.org/wcmsp5/groups/public/_ed_dialogue/-actrav/documents/meetingdocument/wcms_434253.pdf

Hammer, N. (2010). Cross-Border Cooperation Under Asymmetry: the Case of an Interregional Trade Union Council. European Journal of Industrial Relations, 16(4), 351-367.

Hanagan, M. (2003). Labor Internationalism: An Introduction. Social Science History, Special Issue: Labor Internationalism, 27(4), 485-499. Recuperado de http:// www.jstor.org/stable/40267823

Harvey, D. (1998). La condición de la posmodernidad. Investigación sobre los orígenes del cambio cultural. Buenos Aires, Argentina: Amorrortu editores.

Hathaway, D. (17-19 de abril de 1997). Mexico's Frente Auténtico del Trabajo: Organizing Beyond the PRI and Across Borders. Meeting of the Latin American Studies Association, Continental Plaza Hotel, Guadalajara, México. Recuperado de http:/ /lasa.international.pitt.edu/LASA97/hathaway.pdf

Hathaway, D. (2002). El problema de la organización de los sindicatos de las maquiladoras en una economía global antidemocrática. El Cotidiano, 19(116), 45-54. Recuperado de http://www.redalyc.org/pdf/325/32511606.pdf

Kay, T. (2005). Labor Transnationalism and Global Governance: The Impact of NAFTA on Transnational Labor Relationships in North America. American Journal of Sociology, 111(3), 715-756.

Nolan, K. A. (2014). Internalización de las normas laborales internacionales en el marco del tLcan: el caso mexicano. Norteamérica, 9(1), 111-142. Recuperado de http://www.scielo.org.mx/scielo.php?script=sci_arttext\&pid=S1870-35502014000100004\&lng=es\&tlng=es

Papadakis, K. (2011). Shaping Global Industrial Relations. The Impact of International Framework Agreements. Recuperado de: http://www.confindustriaenergia.org/ allegati/Shaping\%20Global\%20Industrial\%20Relation.pdf 
Peters, G. (1998). Comparative Politics. Theory and Methods. En V. Wright (Ed. de la serie), Comparative government $\mathcal{E}$ politics. Recuperado de https://drive.google. com/file/d/0B1P3QNjE7yPmeFdYNVJDOWFsSUlkck40bk5EUURmQXIzaFlj/ view

Rubio, J. (2016). La terminación de políticas y organizaciones públicas. El caso de la extinción de Luz y Fuerza del Centro en México. Revista Gestión y Análisis de Políticas Públicas del Instituto Nacional de Administración Pública de España, Nueva Época, 17(40), 85-96. Recuperado de https://www.researchgate.net/ publication/303444843_Rubio_Jesus_2016_La_terminacion_de_politicas_y_ organizaciones_publicas_El_caso_de_la_extincion_de_Luz_y_Fuerza_del_Centro_en_Mexico_Revista_Gestion_y_Analisis_de_Politicas_Publicas_Instituto_ Nacional_

Sadler, D. (2000). Organizing European Labour: Governance, Production, Trade Unions and the Question of Scale. Transactions of the Institute of British Geographers, 25(2), 135-152. Recuperado de http://www.jstor.org/stable/623188

Sartori, G. (2011). El método de la comparación y la política comparada. En G. Sartori, La política. Lógica y método de las ciencias sociales (pp. 261-318). México: Fondo de Cultura Económica.

Sindicato Mexicano de Electricistas (sme). (20 de octubre de 2013). Apoyo Internacional al SME, Global Power Trade Unions. Recuperado de http://www.sme.org.mx/actividades/2013/2013-10-24apoyointernacionalalSME/reporte.html

Sindicato Mexicano de Electricistas Departamento Cuernavaca. (23 de febrero de 2013). SME. Apoyo internacional a los trabajadores mexicanos [Mensaje en un blog]. Recuperado de http://smecuernavaca.blogspot.mx/2013/02/apoyo-internacional-los-trabajadores.html

Spiegelaere, S. de y Jagodzinski, R. (2015). European Works Councils and SE Works Councils 2015. Facts and Figures. European Trade Union Institute (ETUI). Recuperado de https://www.researchgate.net/publication/282132734_European_Works_ Councils_and_SE_works_councils_2015_Facts_and_figures

UE International Mexican Labor (s.f.). UE E Mexican FAT Federation Organize Mutual Suport. Recuperado de http://www.ueinternational.org/Mexico_info/fat.php

United Students Against Sweatshops (usAs). (s.f.). Garment Worker Solidarity. Recuperado de http:/ / usas.org/campaigns/garment-worker-solidarity/

Wills, J. (1998). Taking on the CosmoCorps? Experiments in Transnational Labor Organization. Economic Geography, 74(2), 111-130. Recuperado de http://www. jstor.org/stable/144278

Jesús Rubio Campos

Mexicano. Doctor en Políticas Públicas por el Tecnológico de Monterrey, maestro en Administración Pública y Política Pública en la misma institución y egresado de la licenciatura en Economía en la Universidad Autónoma de Nuevo León. Es profesor investigador titular en El Colegio de la Frontera Norte. Sus líneas de investigación son los estudios laborales y el análisis de políticas públicas. Su publicación más reciente es del 2017, Sindicalización y precariedad laboral en México. Región y Sociedad, 29(68), $37-75$. 